\title{
Design and Development of Solar Dryer Cabinet with Thermal Energy Storage for Drying Chilies
}

\author{
Vaibhav. V. Pakhare* and Sanjay .P. Salve \\ Department of Mechanical Engineering, Savitribai Phule Pune University, Maharashtra, India \\ Accepted 15 June 2016, Available online 20 June 2016, Special Issue-5 (June 2016)
}

\begin{abstract}
Drying is a one of the essential process for the preservation of agricultural food products. Products, especially fruits require hot air in the temperature range of $45-60^{\circ} \mathrm{C}$ for safe drying. In this, work has been made to develop the compact and portable forced convection solar dryer for drying chilies with thermal energy storage. The performance of the solar dryer has been tested experimentally. Solar dryer is having capacity of $15 \mathrm{~kg}$ of perishable food items and it consist of the flat plate collector based air heating system with thermal energy storage, which used Paraffin wax as phase change material (PCM). The effect of mass flow rates of air on the temperature of the collector, dryer chamber, drying rate and drying time with and without implementation of thermal energy system has also been tested. The efficiency of solar collector and solar dryer has been calculated. Result shows that drying of chilies is technically feasible as comparison with literature, also the moisture content and the reduction in drying time. Temperature in drying chamber was observed 6-9 ${ }^{\circ} \mathrm{C}$ higher than the ambient temperature after sunshine hours up to 6-7 hours. Drying time for the chilies was found to be 17 hours with thermal energy storage system. In this present work, testing and experiment has been carried out in different cases: 1) Mass flow rate of air varies from 0.006, 0.008 and 0.01 $\mathrm{kg} / \mathrm{s}$. 2) With and without phase change materials.
\end{abstract}

Keywords: Solar energy, Open drying, Thermal energy storage, Chili drying.

\section{Introduction}

Solar energy is one of the greatest source of renewable energy and it is referred to as the energy that comes from the sun's rays. Solar energy can be utilized in many ways, like, including heating houses, providing electricity, distillation of sea water. Energy is a form of solar power that is used to do many different things. Among the various applications solar drying is one of the important application. Solar dryers are uses the air collectors to collect the solar energy. The purpose of solar drying is to minimize the moisture content of products to a level that can prevents its spoilage. Drying takes place by two processes first is heat transfer to the product using energy from the heat and mass transfer of moisture from the inner part of the product to its surface and second is from the surface to the surrounding air. Traditionally the farmers use the open drying technique, which achieves by using solar radiation intensity, ambient temperature of air, humidity of ambient air and wind speed. In this method the food and perishable items are directly placed on the ground floors, which can reach higher than the temperatures in open drying, and left there for a number of days to dry.

*Corresponding author: Vaibhav. V. Pakhare
The purpose of solar dryer is to supply more hot air to the product than that the air available naturally and reducing the relative humidly of air. There are two types of solar dryers: one is that uses the solar energy as the only source of heat $i$.e direct mode type and the other that use solar energy to heat the air and this air transfer to products. The airflow in the dryer can be natural convection or forced convection by a blower. In the dryer, the products can directly expose to solar radiation for drying or using the dryer or a combination both. In the dryer the product is heated by the flowing of the heated through the air to the product directly. The transfer of heat to the product is by forced convection from the flowing air on to the food products, which is at a higher temperature than that of the product by direct radiation from the open drying, and by conduction from heated surfaces of product in contact with the product.

There are three types of Thermal energy storage systems are Sensible heat storage, Latent heat storage; and Thermo-chemical storage. In sensible heat storage (SHS) the amount of energy is stored by the material is by raising the temperature of a solid or liquid is called sensible heat storage. Which can use the heat capacity and change in temperature of the material during the process of charging or discharging. Latent heat storage (LHS) uses the phase change of the materials. The heat 
is absorbed or released when the storage material undergoes a change of one phase from solid to other liquid phase, liquid to gas at more or less constant temperature. The materials used for the latent heat storage are called phase change materials (PCM).

Dilip Jain and Pratibha Tewari dries of herbs for their color and flavor is required .In the current paper the study carried out on the solar crop dryer with thermal energy storage with natural convection mode. $50 \mathrm{Kg}$ thermal energy storage materials is attached with dryer The effect of phase change material in solar dryer is to stored energy in day time and release this energy in night or evening time.

Sopian.K. In this present paper they study the different solar dryers as direct, indirect and mixed mode and compare their results. They also discussed the potential of dying agricultural products. In the various regions of country. Solar energy plays important role in the active and passive mode type of solar dryers.

Forson.K. In this present paper they develop solar crop dryer of the mixed mode drying method. In the experiment they used the cassava of $160 \mathrm{~kg}$ by mass, with the $12 \%$ of drying efficiency in the 30-36 hours drying time. The moisture content is reduced to $17 \%$ from $67 \%$ by wet basis.

Shala.S. In the current paper solar dryers with Phase change Materials as an energy storage medium is studied. By using the PCM the drying efficiency improves and also the heat loss is reduced. Various methods are given to improve the thermal conductivity of paraffin wax are given .Mostly the carbon fibers are used and other common are expanded graphite particles are introduced in paraffin.

Bal.L. the work carried out by them thermal energy storage technology in the both ways as sensible Storage and latent storage systems is used in drying of agricultural food products. Drying was carried out on evening to till midnight.

Monia .C, In this paper they found that temperature in dryer chamber is $2.5-7.5^{\circ} \mathrm{C}$ more than ambient temperature of air after sunshine for at least five hours. This experiment is done with indirect solar dryer with PCM as energy storage medium studied. In the experiment prototype consist of two solar air heater, drying compartment, TES storage unit and centrifugal blower.

\section{Design and development of experimental setup}

The design and development of experiment setup consists of the different parts such as flat plate collector, thermal energy storage system as PCM consisting aluminum trays, dryer cabinet and blower. The basis of the criteria mentioned, the design of the individual parts were done and corresponding parameter like relative dimensions of solar flat plate collector, dryer cabinet and thermal energy storage were designed.

The overall project is designed for drying of fruits and perishable based on the area below the collector and tilt angle of the collector on south facing.

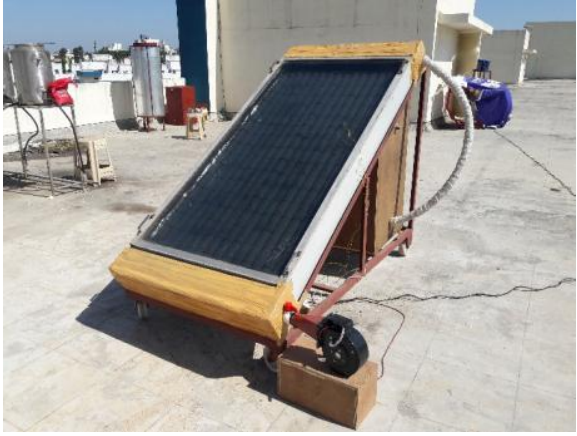

Fig.1 Solar dryer experimental setup

\subsection{Dryer Chamber}

The dryer chamber of the main part of solar dryer it was designed for the forced convection mode method. Material used was plywood and polystyrene (Thermocol). The dimensions of dryer chamber are: Length $=1.0 \mathrm{~m}$, Width $=0.6 \mathrm{~m}$, Height $=0.8 \mathrm{~m}$

\subsection{Thermal Energy Storage}

Thermal energy storage is to store the solar energy during day time and utilize in evening time .TES was done by using the Phase change material as latent heat storage. PCM was used is paraffin wax. Specification are

PCM storage type: trays

Material of trays used: Aluminum

Dimension of aluminum trays:

Length of tray $(\mathrm{L})=0.8 \mathrm{~m}$

Width of tray $(\mathrm{W})=0.56 \mathrm{~m}$

Height of tray $(\mathrm{H})=0.025 \mathrm{~m}$

\subsection{Properties of Paraffin Wax (P48-50)}

\begin{tabular}{|c|c|}
\hline Name & Paraffin wax 48-50 \\
\hline Heat of fusion & $180 \mathrm{~kJ} / \mathrm{Kg}$ \\
\hline Melting point & $48-50{ }^{\circ} \mathrm{C}$ \\
\hline Heat conductivity & $0.59 \mathrm{~W} / \mathrm{m}^{\circ} \mathrm{C}$ \\
\hline Volume expansion & 8 to $9 \%$ \\
\hline Density & $900 \mathrm{Kg} / \mathrm{m}^{3}$ \\
\hline Specific heat & $2.45 \mathrm{~kJ} / \mathrm{Kg} . \mathrm{k}$ \\
\hline
\end{tabular}

\subsection{Flat Plate collector}

The Flat Plate collector is used for heating of the air which was further supplied to the dryer chamber. Dimensions of the flat Plate air collector are: Insulation material $=$ Rockwool of $25 \mathrm{~mm}$ thickness Length $\times$ Width $\times$ Height $=2 \mathrm{~m} \times 1 \mathrm{~m} \times 0.1 \mathrm{~m}$ Length of absorber plate: $1.7 \mathrm{~m}$ and Width of absorber plate: $0.9 \mathrm{~m}$

\subsection{Blower}

Blower is implemented for carrying out forced convection. 
The specifications of the blower are:

Type of blower :- Centrifugal blower

Volume flow rate : -240 CFM

Motor power :- $30 \mathrm{~W}$

\subsection{Multipoint TemperatureIndicator}

$$
\begin{array}{ll}
\text { Input } & :- \text { Thermocouple (K) type } \\
\text { Display } & :- \text { Digit Red Led 3mm Height } \\
\text { Range } & :-0 \text { to } 400 \text { Deg. C. } \\
\text { Channels } & :-8 \\
\text { Selection :- Rotary Switch } \\
\text { Power :- } 230 \mathrm{~V} \text { AC, } 50 \mathrm{~Hz} . \\
\text { Size } \quad:-96 \times 96 \times 80 \mathrm{~mm}
\end{array}
$$

\subsection{TemperatureSensorfor air temperature}

$$
\begin{array}{ll}
\text { Type } & :- \text { Thermocouple Cr/Al(K) type } \\
\text { Assembly } & :- \text { Transition type } \\
\text { Sheath } & :- \text { SS304 } \\
\text { Temp. Range :- }-25 \text { to 300Deg C } \\
\text { Cable } & :-2 \text { mtr. Teflon/Teflon Cable }
\end{array}
$$

\subsection{Anemometer}

$$
\begin{array}{ll}
\text { Type } & \text { :- Flow type } \\
\text { Range } & :-0.0-30 \mathrm{~m} / \mathrm{s} \\
\text { Resolution } & :-0.01 \mathrm{~m} / \mathrm{s} \\
\text { Accuracy } & : - \pm 2 \% \\
\text { Relative } & :-10-80 \% \\
\text { Humidity (RH) } & \\
\text { Resolution of } & :-0.1 \%
\end{array}
$$

Dimensions :- $165 \times 85 \times 38 \mathrm{~mm}$

\subsection{Equations used}

Energy required for drying a particular product:

1) Due to product temp. Up to drying air temperature in the form of Sensible Heat

$$
\mathrm{Q}_{1}=\mathrm{M}^{\prime} \cdot \mathrm{C}_{\mathrm{P}} \Delta \mathrm{t}
$$

2) Latent heat of vaporization for removal of moisture

$$
\mathrm{Q}_{2}=\mathrm{M}^{\prime} . \mathrm{L}
$$

Where $\mathrm{M}^{\prime}=$ quantity of moisture

Removed in $\mathrm{Kg}$

$\mathrm{C}_{\mathrm{P}}=$ Specific heat if product in $\mathrm{kJ} / \mathrm{kg} \cdot \mathrm{K}$

$\mathrm{L}=$ Latent heat of vaporization in $\mathrm{kJ} / \mathrm{kg}$

Losses like thermal insulation of material construction, area in contact of drying air can be predicted.

3) Total energy required for drying is $Q=Q_{1}+Q_{2}+$ losses.

Amount of moisture to be removed can be calculated as

$$
M^{\prime}=\frac{\mathrm{Imc}-\mathrm{Fmc}}{100-F m c} \times M
$$

Moisture content of substance is express as percentage by weight on wet basis and dry basis. The moisture content based on dry basis

$$
\mathrm{m}=\frac{\mathrm{m}_{\mathrm{w}}-\mathrm{m}_{\mathrm{d}}}{\mathrm{m}_{\mathrm{d}}}
$$

Moisture content on wet basis

$$
\mathrm{m}=\frac{\mathrm{m}_{\mathrm{w}}-\mathrm{m}_{\mathrm{d}}}{\mathrm{m}_{\mathrm{W}}} \times 100
$$

The energy balance equation for absorber is heat gained to the total heat loosed by the heat absorber plate of the solar collector

$$
I_{t} \cdot A_{c}=q_{u}+q_{l}
$$

Useful heat gain by absorber plate is given as

$$
\mathrm{q}_{\mathrm{u}}=\mathrm{A}_{\mathrm{p}} \cdot \mathrm{S}-\mathrm{q}_{\mathrm{l}}
$$

Heat loss from the collector is given as

$$
\mathrm{q}_{\mathrm{l}}=\mathrm{U}_{\mathrm{l}} \cdot \mathrm{A}_{\mathrm{p}}\left(\mathrm{T}_{\mathrm{pm}}-\mathrm{T}_{\mathrm{a}}\right)
$$

Heat loss from collector is sum of the heat loss from top, bottom and the sides.

Collector efficiency factor

$$
\mathrm{q}_{\mathrm{l}}=\mathrm{q}_{\mathrm{t}}+\mathrm{q}_{\mathrm{b}}+\mathrm{q}_{\mathrm{s}}
$$

$$
\mathrm{F}^{\prime}=\left(1+\frac{\mathrm{U}_{\mathrm{l}}}{\mathrm{h}_{\mathrm{e}}}\right)^{-1}
$$

Collector heat removal factor it measure of thermal resistance encountered by the absorbed solar radiation in reaching the collector fluid.

So Useful heat gain

$$
\mathrm{F}_{\mathrm{R}}=\frac{\dot{\mathrm{m}} \mathrm{C}_{\mathrm{p}}}{\mathrm{U}_{\mathrm{l}} \mathrm{A}_{\mathrm{p}}}\left[1-\exp \left\{-\frac{\mathrm{F}^{\prime} \mathrm{U}_{\mathrm{l}} \mathrm{A}_{\mathrm{p}}}{\dot{\mathrm{m} \mathrm{C}_{\mathrm{p}}}}\right\}\right]
$$

$$
\mathrm{q}_{\mathrm{u}}=\mathrm{F}_{\mathrm{R}} \mathrm{A}_{\mathrm{p}}\left[\mathrm{S}-\mathrm{U}_{\mathrm{l}}\left(\mathrm{T}_{\mathrm{fi}}-\mathrm{T}_{\mathrm{a}}\right)\right]
$$

Instantaneous efficiency of collector is given as

$$
\begin{gathered}
\eta=\frac{\text { Useful heat gain }}{\text { Radiation incident on the collector }} \\
\eta_{\mathrm{i}}=\frac{\mathrm{q}_{\mathrm{u}}}{\mathrm{I}_{\mathrm{T}} \times \mathrm{A}_{\mathrm{c}}}
\end{gathered}
$$

System drying efficiency is defined as the ratio of energy supplied to evaporate the moisture of the product to the heat supplied to the drier. Heat supplied to drier is solar radiation.

$$
\grave{\eta}=\frac{\mathrm{L}_{\mathrm{v}} \times \mathrm{M}_{\mathrm{e}}}{3600 \times \mathrm{A}_{\mathrm{c}} \times \mathrm{I}_{\mathrm{t}}+\mathrm{P}_{\mathrm{b}}}
$$

\section{Methodology}

Testing methodology carried out in such way that to find the drying time, moisture content, Efficiency of the dryer and collector with and without implementation of phase change materials in developed solar dryer.

1) The effect of various mass flow rates of air on moisture content, drying rate, solar collector temperatures and dryer efficiency has been tested.

2) The mass flow rate of air kept for the individual set of testing at $0.006,0.008,0.01 \mathrm{~kg} / \mathrm{Sec}$ though the dryer cabinet with the help of anemometer.

3) Testing has been carried out for drying of chili from initial moisture content of $79 \%$ to final moisture content up to $15 \%$ with implementation of a thermal energy storage system.

4) With the selected mass flow rate of air, reduction in weight of the sample chilies, Outlet temperature of the collector, dryer cabinet exit temperature, was noted.

5) The inlet and outlet temperatures of the collectors, dryer chamber temperature, and dryer, relative humidity in dryer chamber is recorded. 


\section{Results and discussions}

The results obtained from the experimental testing are carried out on the solar dryer are presented in this section. Various groups are plotted for the study of variation of solar radiation to time, study of the effect of various mass flow rates, drying time, the variation in the efficiency of flat plate collector etc.

\subsection{Solar radiation intensity Vs Time.}

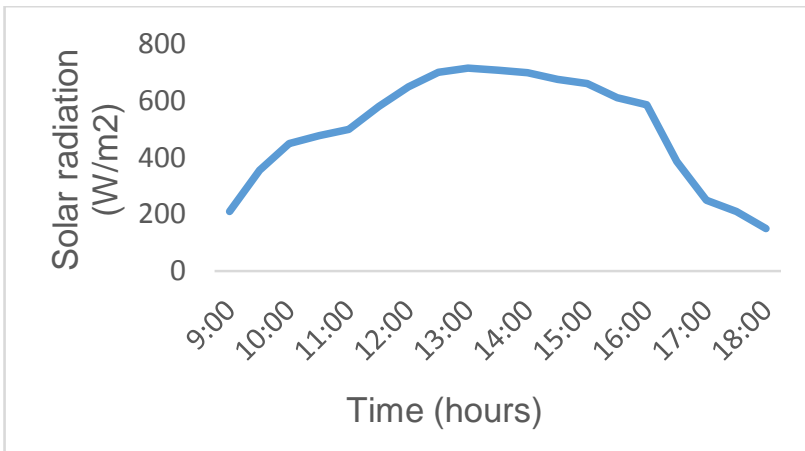

Fig.2 Variation of solar radiation vs time

4.2 Outlet temperature of collector and dryer chamber temperature with TES

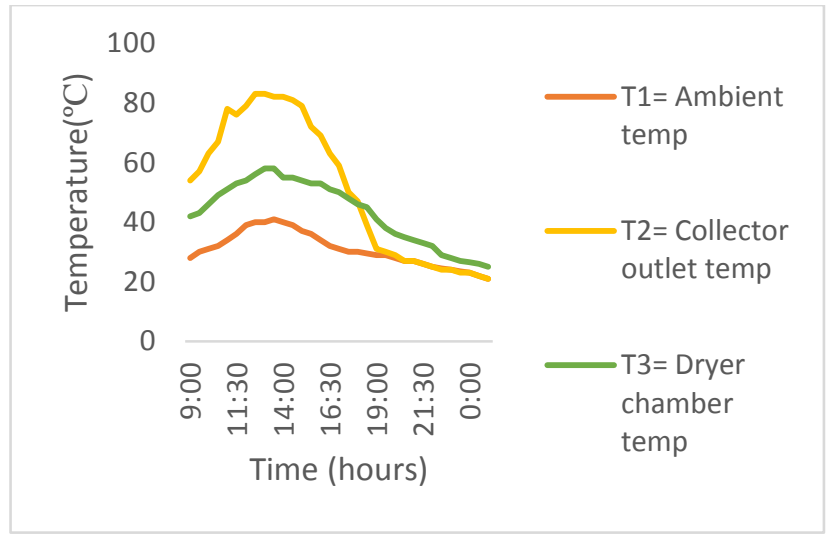

Fig.3 Variation of temperature vs time

\subsection{Efficiency of Flat plate collector Vs Time}

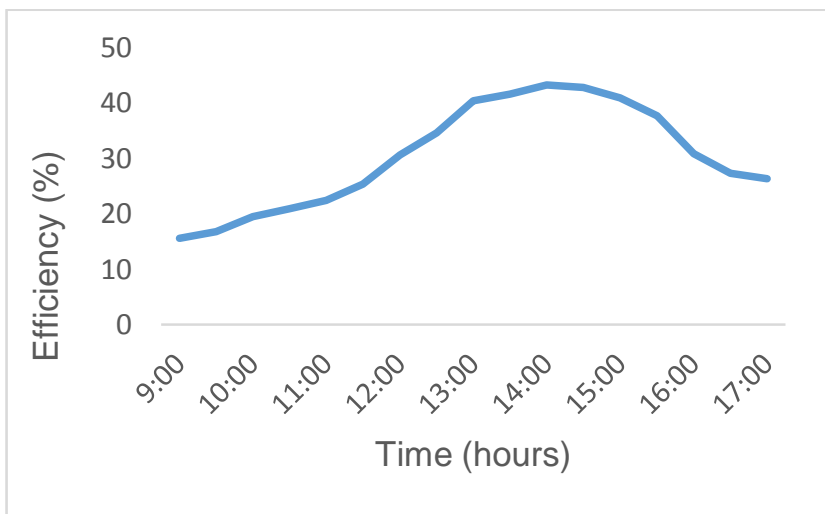

Fig.4 Variation of efficiency vs time

\subsection{Moisture content Vs Time}

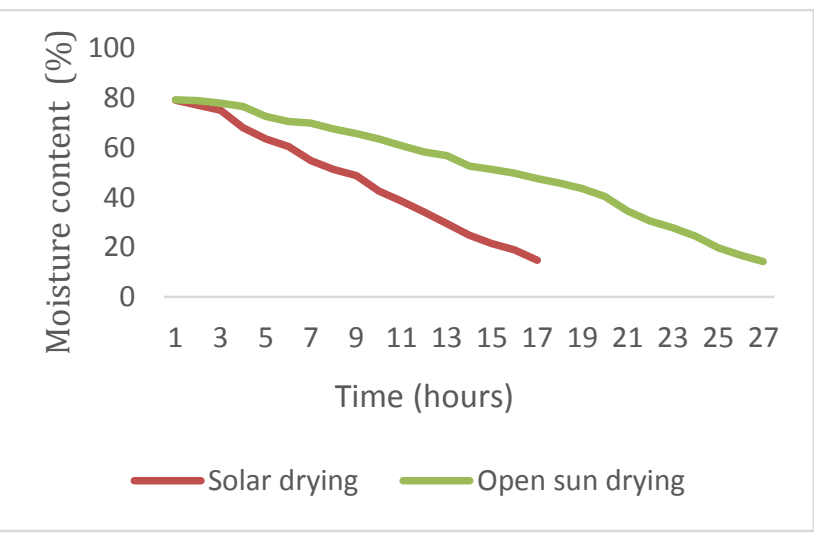

Fig.5 Variation of moisture content vs time 4.5 Temperature Vs Different mass flow rates.

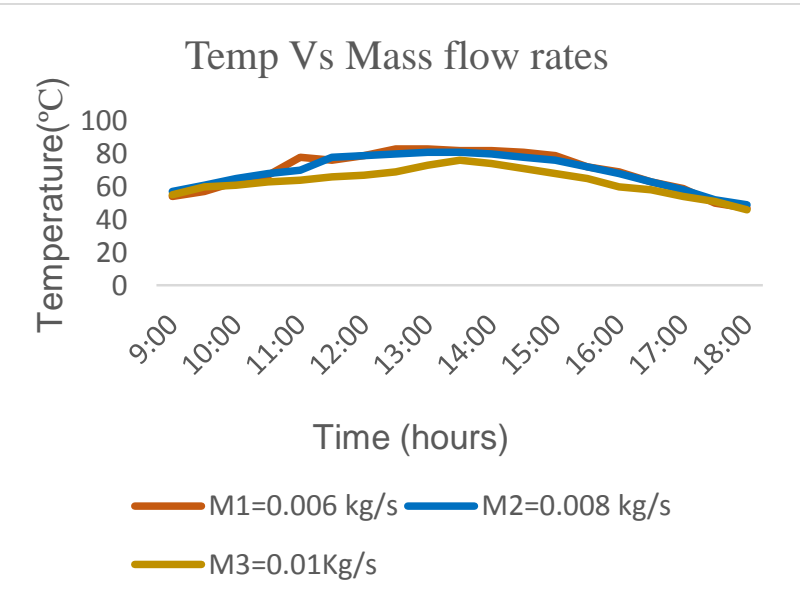

Fig.6 Variation of temperature vs time 4.6 Relative Humidity of air Vs Time.

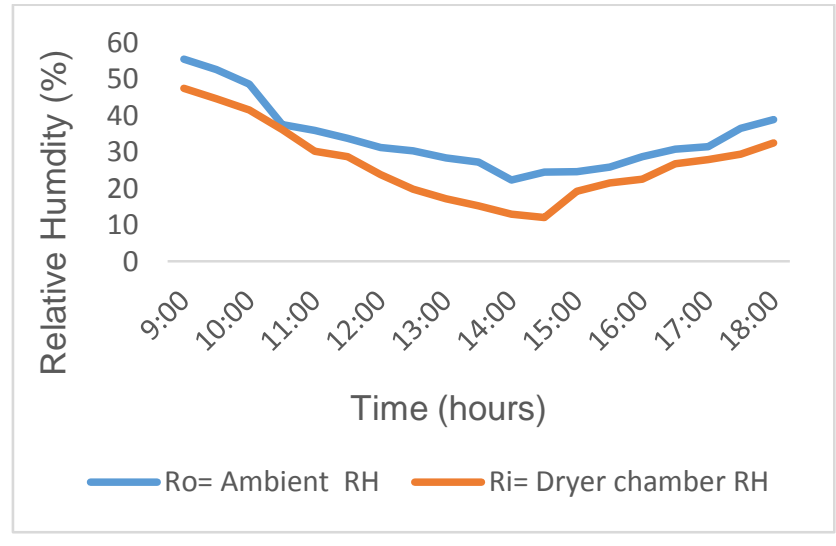

Fig.7 Variation of relative humidity vs time

From the above graphs we can conclude that maximum solar radiation intensity is at $716 \mathrm{~W} / \mathrm{m}^{2}$ at $1: 30 \mathrm{PM}$ from the weather monitoring system at Pimpri chinchwad college of engineering and the maximum 
flat plate collector exit temperature is $83^{\circ} \mathrm{C}$ at $2: 00 \mathrm{PM}$ for mass flow rate $0.006 \mathrm{~kg} / \mathrm{s}$. Efficiency of flat plate collector for forced convection is maximum at 1 to 2 PM which was $43 \%$. Weight of chilies was reduced to $0.248 \mathrm{~kg}$ from $1 \mathrm{~kg}$ of chillies in 17 hours. Relative Humidity in dryer chamber is lower than ambient which improves the drying process and as well as it has tendency to remove moisture from food products.

\section{Conclusions}

In this work forced mode convection solar dryer with thermal energy storage has been developed and tested. The developed solar dryer with a phase change material is used for drying food items in the evening and till midnight hours also. The variations of the mass flow rate of air on temperatures, drying time is studied, as mass flow rate increases the exit temperature of collector was decreases and the dryer efficiency was found $22 \%$ at the same time effect of thermal energy storage on drying time on chilies also tested with and without implementation of thermal energy storage. The drying experiment tested with chilies and the complete drying process completed with 17 hours in solar dryer, for open drying it takes place around 27 hours which was $38 \%$ less as compared with open sun drying. Incorporation of the thermal energy storage system reduces drying time .Utilization of thermal energy storage the drying time for a particular day can be extended from sunshine hours to non-sunshine hours. The temperature in drying chamber was observed $6-9{ }^{\circ} \mathrm{C}$ higher than the ambient temperature for at least 6-7 hours.

\section{Acknowledgement}

I would like to thanks to all my college faculty members and my project guide Prof. S. P. Salve sir, for inspiration and timely guidance. And also to my PG Coordinator Prof. Dr. N.R. Deore, sir for consistent encouragement for completing my research work successfully.

\section{References}

Jain.D, Tewari.P, Performance of indirect through pass natural convective solar crop dryer with phase change thermal energy storage,, Renewable and Sustainable Energy Reviews,vol.34,pp.463-470,2015

Sopian.k, Performance analysis of solar drying system for red chili, Solar energy, vol.99, pp.47-54, 2014

Forson.K,Design of mixed-mode natural convection solar crop dryers: Application of principles and rules of thumb, Renewable Energy,vol.32,pp.2306-2319,2007

Shala.S,Bek.A, Solar dryers with PCM as energy storage medium: A review, Renewable and Sustainable Energy Reviews, Vol.33, pp110-116, 2014

Bal.L ,Satya.S,Solar dryer with thermal energy storage systems for drying agricultural food products: A review, Renewable and Sustainable Energy Reviews,vol.14,pp.22982314,2009

Monia .C, Experimental investigation of a novel indirect solar dryer implementing PCM as energy storage medium, Energy Conversion and Management, vol-83, pp-1-8, 2014 